
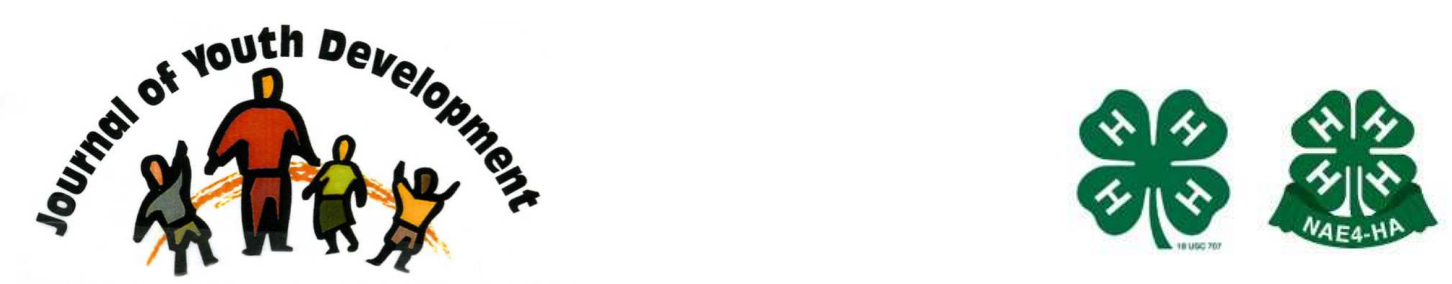

Bridging Research \& Practice

\title{
Using Community-Based Programming to Increase Family Social Support for Healthy Eating among African American Adolescents
}

\author{
Joel E. Williams \\ Department of Public Health Sciences \\ Clemson University \\ Clemson, SC \\ joel2@clemson.edu \\ Sarah F. Griffin \\ Department of Public Health Sciences \\ Clemson University \\ Clemson, SC
}

\author{
Amy S. McCune \\ 4-H National Headquarters \\ National Institute of Food and Agriculture, USDA \\ Washington, DC \\ Gregory H. Linke \\ 4-H Youth Development \\ Clemson University \\ Clemson, SC
}




\title{
JOURNAL OF YOUTH DEVELOPMENT \\ bridging research and practice

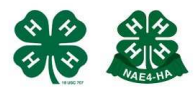

Bridging Research \& Practice

Volume 05, Number 03, Fall 2010

Article 100503RS001

\section{Using Community-Based Programming to Increase Family Social Support for Healthy Eating among African American Adolescents}

\author{
Joel E. Williams, Sarah F. Griffin, and Gregory H. Linke \\ Clemson University \\ Amy S. McCune \\ National Institute of Food and Agriculture, USDA
}

\begin{abstract}
Little is known about emotional and instrumental social support for nutrition behaviors among African-American adolescents. In this paper, we specifically examine intervention effects on emotional, instrumental and total (composite) social support for fruit/vegetable and low-fat dairy intake. Data from a larger intervention, based on Social Cognitive Theory, which was implemented with 38 African-American adolescents and their families to increase fruit/vegetable intake, low-fat dairy intake and physical activity behaviors are presented. One-way ANOVA analyses revealed that intervention participants had positive and significant increases in emotional social support for low-fat dairy intake $(P=0.01)$, total social support for fruit/vegetable intake $(P=0.05)$, and total social support for low-fat dairy intake $(P=0.02)$. Specific recommendations addressing family social support for healthy eating through youth development programming are discussed.
\end{abstract}

\section{Introduction}

In 1983, a report from the U.S. Department of Health and Human Services revealed that the overall health of the nation was improving, but there were significant racial disparities (U.S. Department of Health and Human Services, 1983). Now, more than 20 years later, the problem of health disparities persists (Fuller, 2003). Four of the six causes of death that still disproportionately affect minorities are related to nutrition (i.e., cardiovascular disease, cancer, diabetes, infant mortality). Professionals involved in health promotion programming with youth need proven methods to intervene on specific nutrition behaviors related to health disparities. Family-based interventions aimed at influencing social support for healthy eating may be an effective avenue. 


\section{Adolescents and Nutrition}

There is a trend for the consumption of fruits and vegetables among children to decline with age. Further, differences in fruit and vegetable consumption among racial/ethnic groups have been noted from childhood through adulthood. (Center for Nutrition Policy and Promotion, 2001). At least one study has shown that racial differences in vegetable intake were not significant, but African-American adolescents did report consuming significantly more fruits than Caucasian adolescents (Brady, et al., 2000). A similar study revealed that African-American adults reported consuming fewer fruits and vegetables than Caucasians (Kumanyika \& Odoms, 2001). These findings underscore the importance of intervening early with African-American adolescents in order to maintain and improve their levels of fruit and vegetable consumption across the lifespan.

Milk and other dairy products are the major source of calcium in the U.S. food supply, contributing $72 \%$ of the available calcium in American diets (Miller, Jarvis \& McBean, 2001). Milk has a higher concentration of calcium as compared to other foods, and milk is fortified with vitamin $D$, which increases calcium absorption (Standing Committee on the Scientific Evaluation of Dietary Reference Intakes, Food and Nutrition Board, \& Institute of Medicine, 1999). Without consuming dairy products, it is difficult to meet the dietary calcium recommendations (Food Surveys Research Group, 1999). However, according to data from the 1994-96 Continuing Survey of Food Intakes by Individuals, Americans two years old and older consumed an average of 1.5 servings of dairy per day; the Food Guide Pyramid recommendations are two to three servings per day (Neumark-Sztainer, et al., 1997). Intake of milk and other dairy products has been shown to decrease between six and eleven years of age (Grunbaum, et al., 2002; Neumark-Sztainer, et al., 1997; Standing Committee on the Scientific Evaluation of Dietary Reference Intakes, Food and Nutrition Board, \& Institute of Medicine, 1999). Additionally, when comparing race and gender, Caucasian girls report a $4 \%$ higher prevalence of milk consumption than African-American girls and Caucasian boys report a $6 \%$ higher prevalence of milk consumption than African-American boys (Gillum, 1991). This racial discrepancy in milk and dairy intake for adolescents may be due to the higher proportion of lactose intolerance among African-Americans and may reflect cultural eating habits modeled from parent to child (Kumanyika \& Odoms, 2001; Standing Committee on the Scientific Evaluation of Dietary Reference Intakes, Food and Nutrition Board, \& Institute of Medicine, 1999).

Compared to Caucasians, African-American children and adolescents are at a higher risk for developing essential hypertension and cardiovascular disease in early adulthood. The consumption of fruits, vegetables and low-fat dairy can greatly reduce this risk (Gillum, 1991). A subgroup analysis of hypertensive African-Americans in the Dietary Approaches to Stopping Hypertension (DASH) study demonstrated a greater blood pressure lowering effect when participants consumed a diet emphasizing fruits, vegetables and low-fat dairy. In the DASH study, a control group who ate a diet emphasizing fruits and vegetables reduced systolic blood pressure by $8.0 \mathrm{~mm} \mathrm{Hg}$ and diastolic blood pressure by $3.4 \mathrm{~mm} \mathrm{Hg}$. An intervention group who ate a diet emphasizing fruits, vegetables and low-fat dairy, reduced systolic blood pressure by $13.2 \mathrm{~mm} \mathrm{Hg}$ and diastolic blood pressure by $6.1 \mathrm{~mm} \mathrm{Hg}$ (Svetkey, et al., 1999). Increased calcium intake via low-fat dairy products greatly improved blood pressure outcomes in this study compared to a diet emphasizing fruits and vegetables. 


\section{Family-based Interventions}

Family greatly impacts behavioral development of children (Baranowski \& Nader, 1985), and has been characterized as the greatest overall influence on a child's health (Roberts \& Wallander, 1992). Regarding dietary intake, family factors have been shown to affect food preferences and subsequent eating behaviors (Sallis \& Nader, 1988). Families influence children and young adolescents through social support. Family support for diet has been shown to be more highly correlated to dietary intake than support from friends, although peer influences increasingly impact behavior as adolescents become more autonomous (Sallis, et al., 1987). Nevertheless, intervention studies have shown that families can significantly impact dietary knowledge, attitudes, self-efficacy and behavioral intention (Crockett, et al., 1989), metabolic control (Hanson, et al., 1995), and weight loss (Wadden, et al., 1990) among children and young adolescents.

Nader, et al. (1983) reported on an intervention with 24 families (8 each: African-American, Mexican-American, and Caucasian) with children in the third to sixth grades. The significant treatment effects for social support resulting from this study indicated that family based, social environment-focused interventions were both feasible and important. Perry, et al. (1988) reported on a study comparing a school-based program to an equivalent home-based program with 2,250 elementary students in Minnesota targeting reductions in dietary fat consumption and sodium intake. Students in the home-based program reported more behavior change, showed reduced total fat and saturated fat measured via dietary recall and had more of the "program encouraged" foods on their food shelves, as compared to the school-based program students.

The Child and Adolescent Trial for Cardiovascular Health (CATCH) was a multi-state efficacy study examining the effects of an intervention to reduce cardiovascular risk factors among adolescents (Edmundson, et al., 1996; Nader et al., 1996). The intervention schools involved school-based intervention or school-based intervention plus a family treatment plan. Significant intervention effects were observed for perceived social reinforcement for healthy food choices, improved knowledge, intentions, and self-efficacy. Girls reported significantly greater perceived reinforcement for healthy eating than did boys.

The findings of these studies suggest interventions involving families may be effective avenues for promoting healthy nutrition. The family, as a socially-supportive environment, may in turn reinforce and sustain behavioral changes. The purpose of this paper is to examine the effects of a community-based intervention on family social support for healthy eating. The data were obtained from a larger study designed to promote healthy eating and physical activity among African American families (Wilson, et al., 2004).

\section{Methods}

\section{Participants}

The larger study utilized a quasi-experimental, pretest/posttest intervention design with a control group. Intervention and control groups met at one of two community centers. Participants for the intervention study were recruited from adolescents involved in general health screenings at community- and church-based centers. Eligibility requirements included being between the ages of 10 and 15 years of age, weighing less than or equal to the 95th percentile body mass index (BMI) for age and gender, African-American race, with normal blood pressure, and not taking medications known to affect blood pressure. Adolescents were invited 
to participate in the study via phone call solicitation to their parents. During the phone call, parents were asked if they had other children between the ages of 10-15 who would also like to participate, pending screening for eligibility. A control group (attention control) also met once per week for the same duration of time as the intervention groups and participated in a general health education class that did not emphasize changing nutrition or physical activity behaviors.

Examples of topics covered in the comparison group included alcohol and other drug use prevention, HIV/STD/Teen pregnancy prevention, stress management, and study skills. In total, 38 African-American adolescents and their mothers participated in the study. Table 1 presents study participant characteristics.

\section{Data Collection}

All mothers completed an IRB approved parental consent form and all adolescents completed an IRB approved assent form. Mothers completed demographic surveys, trained staff measured adolescents' height and weight, and adolescents completed paper and pencil psychosocial scales. Measures were administered to the adolescents in small groups (without mothers in the room) with one-to-one help provided by trained staff, prior to and after intervention participation. Week one involved obtaining baseline information such a food intake and educating the participants on serving sizes. At the end of the last session, the same (post-test) measures were completed by all adolescents.

\section{Intervention Description}

Adolescents and at least one of their parents (usually the mother) participated in the fivesession intervention. The nutrition intervention goal for the treatment group was to increase fruit and vegetable intake to 6-8 servings per day and low-fat dairy intake to 3-4 servings per day, consistent with previous studies by Wilson et al. (Wilson, Sica \& Miller, 1999; Wilson, et al., 2002), and following modified DASH diet guidelines (Appel, et al., 1997; Sacks, et al., 1999; Sacks, et al., 2001). Social Cognitive Theory (Bandura, 1986) was used to guide the intervention. Environment, self-monitoring, goal setting, behavioral skills, and social supportseeking skills were identified as the most relevant SCT constructs. To address self-monitoring the participants were taught to set weekly food intake goals and record their daily food intake behaviors for each using a dietary and physical activity record. Family members used these records during discussion, problem-solving and goal-setting activities each week. Behavioral skill activities were led by a health psychologist and involved problem solving, goal-setting, practicing positive self-talk, self-reward plans, social support seeking, and long-term maintenance skills. The role of family was always emphasized during these activities by asking the families to have discussions while eating food from the food stations. Each session ended with the families discussing specific behavioral skills with the group. Finally, instructions and preparations for the next session were given.

During this first session adolescents were also asked to indicate on a list, the fruits, vegetables and low-fat dairy foods they liked and disliked in order to determine what healthy foods to provide to the families to facilitate availability and accessibility (environment) of preferred healthy foods in their homes. At the end of session two through session five, adolescents were given individually prepared bags of fruits, vegetables and low-fat dairy items following their documented preferences to facilitate access to healthy foods. Food stations were set up for each session and were designed to teach the families how to prepare snacks and meals emphasizing DASH foods. Each week the recipes were shared with the families and by the end of the intervention, the families were given a book of recipes from all food stations during the intervention and from recipes provided by the family participants. Family members were also 
taught to record their daily food intake behaviors for each week using diet diaries which they used in discussion, problem-solving and goal-setting activities (behavioral skills training) during the sessions. Sessions two through five involved four structured activities: 30 minutes of physical activity, 30 minutes of food preparation, 30 minutes of behavioral skills training, and 30 minutes of discussion. During the last session, families volunteered to bring healthy DASH-style foods prepared at home for all to sample.

\section{Staffing}

Most of the staff leading intervention activities were African-American and were from the community in which the intervention took place. During the sessions, physical activities included stretching, calisthenics, walking and basketball (led by a certified physical education teacher) as well as aerobics (led by a certified aerobic teacher). Food preparation stations were led by a retired nutritionist from the local extension service and a registered dietician from the local hospital system.

\section{Measures}

Modified versions of the Social Support for Eating Scale (Sallis, et al., 1987) and the Inventory of Socially Supportive Behaviors (Barrera \& Ainlay, 1983; Barrera, Sandler \& Ramsay, 1981) were used to measure emotional social support and instrumental social support, respectively. In addition, two versions of each scale were modified to assess social support for fruit/vegetable intake and low-fat dairy intake, respectively. Because the instrumental support scales had not been previously used with African-American adolescents, those instruments were pilot tested for readability and comprehension prior to the intervention study. Appropriate changes to the instruments occurred prior to the intervention study. Pilot testing procedures and forms were approved by [our university's] Institutional Review Board.

\section{Emotional social support for fruit/vegetable intake and low-fat dairy intake} A modified version of the Social Support for Eating Scale (Sallis, et al., 1987) was used to assess emotional social support for fruit/vegetable intake as well as low-fat dairy intake. These instruments emphasized positive and negative emotional social support. Using a five-point Likert-type scale, ranging from 1 (none) to 5 (very often), respondents answered how often family and friends did what was described in each item during the past month. Ultimately, responses to all items on a given instrument were added together to produce a summary score for that instrument. Wilson and Ampey-Thornhill (2001) demonstrated test-retest reliability correlations of $r=.60$ to $r=.84$ for the family social support scale with a sample of $148,13-16$ year old African-American adolescents. The 16-item instrument used by Wilson and AmpeyThornhill is the same Emotional SS F\&V instrument used in the present study.

An alternate version of that instrument, worded for low-fat dairy was also used in the present study to assess Emotional SS LFD, by replacing the words 'fruit and vegetable' with 'low-fat dairy.'

Instrumental social support for fruit/vegetable intake and low-fat dairy intake A review of the literature failed to reveal the existence of social support scales specific to Instrumental SS F\&V or Instrumental SS LFD that have been validated with adolescents. Therefore items from an existing instrument designed to assess general instrumental social support (Barrera \& Ainlay, 1983; Barrera, Sandler \& Ramsay, 1981) were modified to create two separate instruments; one reflecting instrumental social support for fruit/vegetable intake and one reflecting social support for low-fat dairy. Both instruments contained 17 items. Using a five-point Likert-type scale, ranging from 1 (never) to 5 (about every day), respondents 
answered how often during in past month family members did specific activities with/for them. Ultimately, responses to all items on a given instrument were added together to produce a summary score for that instrument.

Composite social support for fruit/vegetable intake and low-fat dairy intake A composite measure of social support for fruit/vegetable intake (Composite SS F\&V) was obtained by adding the summary scores from the emotional support for fruit/vegetable intake and instrumental support for fruit/vegetable intake together. Similarly, a composite measure of social support for low-fat dairy intake (Composite SS LFD) was obtained by adding the emotional and instrumental summary scores from the low-fat dairy instruments.

Fifteen male and fifteen female African-American adolescents, aged 10-15 ( $M=12.0, S D=1.1)$, were recruited from a community-based weekend basketball physical activity program to give feedback (pilot test) on the Instrumental SS F\&V and Instrumental SS LFD scales. This feedback led to the addition of a clarification sentence in the instructions for both instruments that indicated some items refer to meals and some to snacks, changes made prior to use in the intervention study.

\section{Analyses}

The present analysis focuses on intervention effects on social support for healthy nutrition behavior. All analyses were performed using SPSS version 11.5. Descriptive statistics were produced to describe the sample and to examine treatment group differences at baseline. Sample demographics from the intervention study are presented in Table 1. Means and standard deviations were calculated for continuous variables; frequencies and percentages were calculated for categorical variables. Correlation analyses were conducted to determine if any participant demographic or behavioral variables co-varied with social support dependent variables. Analysis of variance (ANOVA) was performed to examine treatment effects on change in social support (change score $=$ post-test social support summary score minus pre-test social support summary score) for each type of social support (Emotional Social Support for FV, Emotional Social Support for LFD, Instrumental Social Support for FV, Instrumental Social Support for LFD, Composite Social Support for FV, and Composite Social Support for LFD).

\section{Results}

All participants involved in pre-test data collection completed the study. No significant differences between treatment groups at pre-test were identified. Intervention process evaluation also revealed excellent participation rates ( $>75 \%$ session attendance) by adolescents and parents with no significant differences between groups. 
Table 1

Study participant characteristics by participant treatment group

\begin{tabular}{|c|c|c|}
\hline \multirow[b]{2}{*}{ Characteristics } & \multicolumn{2}{|c|}{ Treatment Group } \\
\hline & $\begin{array}{l}\text { Intervention }{ }^{*} \\
(\mathrm{n}=21)\end{array}$ & $\begin{array}{l}\text { Control } \\
(n=17)\end{array}$ \\
\hline & & \\
\hline Adolescents & & \\
\hline Age, Mean (SD) & $11.7(1.6)$ & $12.0(1.6)$ \\
\hline Body Mass Index, Mean (SD) & $20.9(2.7)$ & $21.4(4.2)$ \\
\hline Male, (Percent) & $47.6 \%$ & $58.8 \%$ \\
\hline Mothers & & \\
\hline Marital Status & Percent $^{+}$ & Percent $^{+}$ \\
\hline Married & $38.1 \%$ & $47.1 \%$ \\
\hline Single, Never Married & $23.8 \%$ & $29.4 \%$ \\
\hline Separated or Divorced & $38.1 \%$ & $11.8 \%$ \\
\hline Missing & $0.0 \%$ & $11.8 \%$ \\
\hline \multicolumn{3}{|l|}{ Highest Grade Attained } \\
\hline Some High School & $14.3 \%$ & $11.8 \%$ \\
\hline High School Graduate & $28.6 \%$ & $17.6 \%$ \\
\hline Some College & $19.0 \%$ & $41.2 \%$ \\
\hline College Graduate & $19.0 \%$ & $11.8 \%$ \\
\hline Professional/Grad School & $14.3 \%$ & $5.9 \%$ \\
\hline Missing & $4.8 \%$ & $11.8 \%$ \\
\hline \multicolumn{3}{|l|}{ Employment Category } \\
\hline Full-time & $57.1 \%$ & $52.9 \%$ \\
\hline Part-time & $19.0 \%$ & $17.6 \%$ \\
\hline Retired & $4.8 \%$ & $17.6 \%$ \\
\hline Unemployed & $14.3 \%$ & $0.0 \%$ \\
\hline Missing & $4.8 \%$ & $11.8 \%$ \\
\hline \multicolumn{3}{|l|}{ Total Family Income } \\
\hline$<\$ 19,999$ & $38.1 \%$ & $17.6 \%$ \\
\hline$\$ 20,000-\$ 29,999$ & $28.6 \%$ & $47.1 \%$ \\
\hline$\geq \$ 30,000$ & $28.6 \%$ & $17.6 \%$ \\
\hline Missing & $4.8 \%$ & $17.6 \%$ \\
\hline
\end{tabular}

${ }^{*}$ Pre-test group differences non-significant

† Percents may not equal to 100 due to rounding 
Table 2 presents pre-test and post-test social support scores by treatment group. No participant variables were significantly correlated with social support change scores.

Table 2

Pre and Post intervention Social Support Scale Scores by Treatment Group

\begin{tabular}{|l|l|l|l|l|l|}
\hline & \multicolumn{2}{|l|}{ Intervention } & \multicolumn{2}{l|}{ Control } \\
\hline $\begin{array}{l}\text { Social } \\
\text { Support } \\
\text { Variables }\end{array}$ & $\begin{array}{l}\text { Pre-Test } * \\
\text { Mean (SD) }\end{array}$ & $\begin{array}{l}\text { Post-Test } \\
\text { Mean (SD) }\end{array}$ & $\begin{array}{l}\text { Pre-Test * } \\
\text { Mean (SD) }\end{array}$ & $\begin{array}{l}\text { Post-Test } \\
\text { Mean (SD) }\end{array}$ \\
\hline $\begin{array}{l}\text { Emotional } \\
\text { for FV }{ }^{\dagger}\end{array}$ & $51.6(7.7)$ & $51.8(8.8)$ & $52.1(8.8)$ & $49.8(10.8)$ \\
\hline $\begin{array}{l}\text { Emotional } \\
\text { Social Support } \\
\text { for LFD }\end{array}$ & $49.1(5.2)$ & $52.7(10.5)$ & $51.7(8.4)$ & $47.2(7.2)$ \\
\hline $\begin{array}{l}\text { Instrumental } \\
\text { Social Support } \\
\text { for FV }\end{array}$ & $41.3(16.5)$ & $53.8(16.7)$ & $55.6(18.4)$ & $53.3(17.2)$ \\
\hline $\begin{array}{l}\text { Instrumental } \\
\text { Social Support } \\
\text { for LFD }\end{array}$ & $38.1(15.4)$ & $49.6(18.9)$ & $49.2(20.8)$ & $46.6(19.3)$ \\
\hline $\begin{array}{l}\text { Composite } \\
\text { Social Support } \\
\text { for FV }{ }^{\dagger}\end{array}$ & $93.1(19.7)$ & $105.6(24.1)$ & $108.3(24.4)$ & $103.1(25.7)$ \\
\hline $\begin{array}{l}\text { Composite } \\
\text { Social Support } \\
\text { LFD }{ }^{\dagger}\end{array}$ & $87.1(17.7)$ & $102.3(27.5)$ & $100.9(27.0)$ & $93.8(24.4)$ \\
\hline
\end{tabular}

* Pre-Test differences not significant

${ }^{\dagger}$ Significant change from pre-test to post-test 
One-way ANOVA analyses revealed that the intervention participants demonstrated significantly greater mean change in social support summary scores for Emotional Social Support for LFD, Composite Social Support for FV and Composite Social Support for LFD than did the control participants. These results are presented in Figure 1.

Figure 1

Change in Social Support Scale Scores by Treatment Group

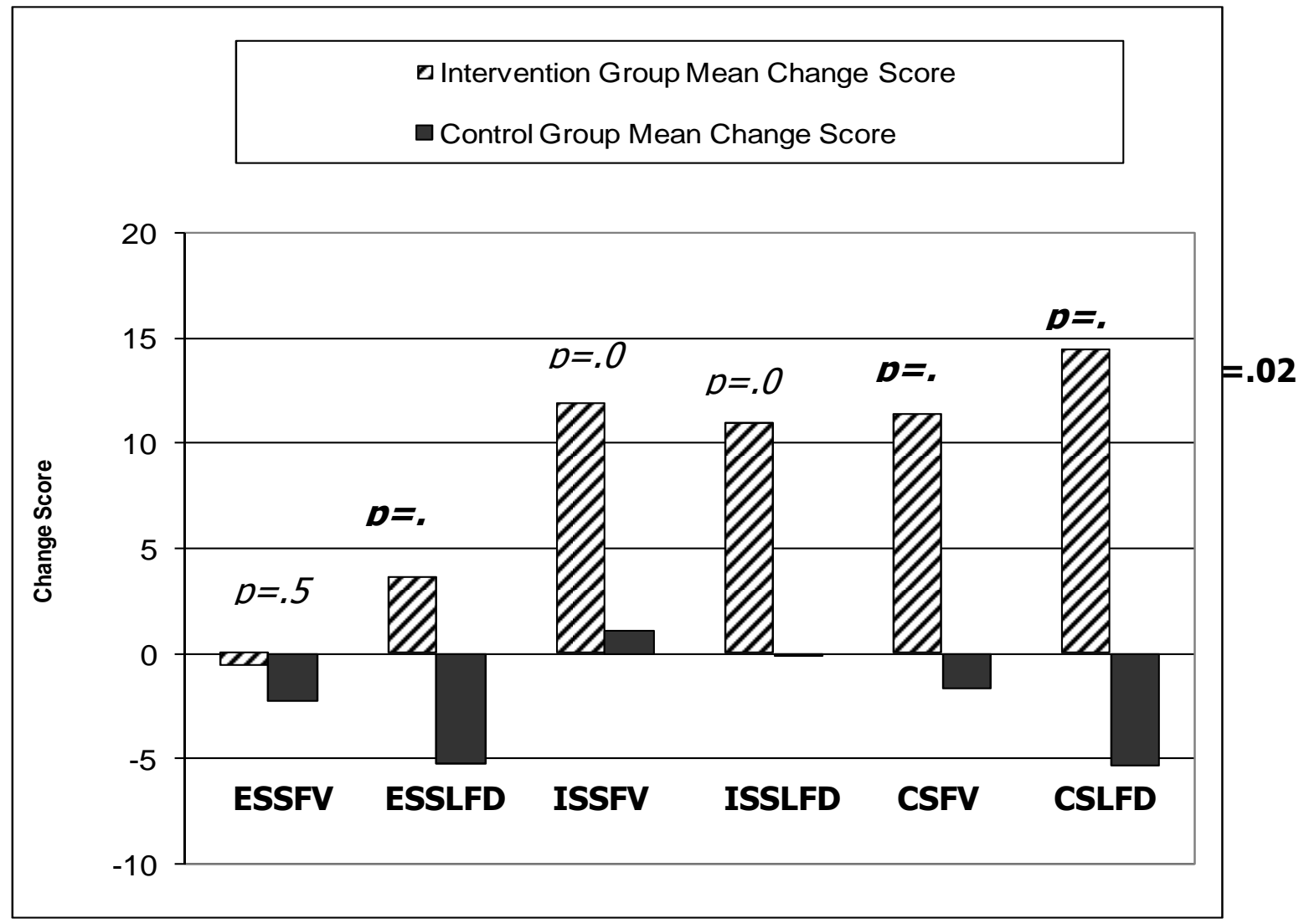

Change Scores were computed as post-test scale score minus pre-test scale score

ESSFV = Emotional Social Support for Fruits and Vegetables

ESSLFD = Emotional Social Support for Low Fat Dairy

ISSFV = Instrumental Social Support for Fruits and Vegetables

ISSLFD = Instrumental Social Support for Low Fat Dairy

CSFV $=$ Composite Social Support for Fruits and Vegetables

CSLFD = Composite Social Support for Low Fat Dairy

More specifically, intervention participants demonstrated a greater mean increase from pre-test to post-test $(P=0.01)$ in Emotional Social Support for LFD $(M=3.6, S D=10.7)$ compared to control group participants $(M=-5.2, S D=6.6)$. Intervention participants also showed a greater mean increase $(P=0.05)$ in Composite Social Support for FV $(M=11.3, S D=22.7)$ compared to control group participants $(M=3.0, S D=11.7)$. Finally, intervention participants had a greater mean increase $(P=0.02)$ in Composite Social Support for LFD $(M=14.4, S D=27.7)$ compared to control group participants $(M=4.2, S D=16.2)$. 


\section{Discussion}

The family focus of this study as an effective avenue for health promotion is supported by the findings of other studies (Edmundson, et al., 1996; Nader, et al. 1983; Nader, et al., 1996; Perry, et al., 1988; Sallis, et al., 1987) in that health behavior may be positively influenced by significant others during the course of the change process and that family members, especially mothers, have important influences on subjective norms related to healthy nutrition. In addition, it may be important for researchers and youth development program staff involved in health promotion programs to explore and attempt to influence social support more broadly. The present study found that total (composite) social support for a given nutrition behavior was affected by the intervention whereas it was more difficult to detect changes in specific types of social support for nutrition behaviors.

The social ecological model (SEM) is a conceptual framework that is useful in translating research to practice. According to SEM, an individual's behavior is determined by factors at various "levels" including: the individual (i.e., "within" the person), interpersonal (interactions "between" people, e.g., 4-H club), community (e.g., in a school or county) and policy levels (i.e., "rules" enforced by national, state, or local entities) (McLeroy, et al., 1988; Stokols, 1996). Further, although an individual's behavior may be influenced predominantly by one level, theoretically, their behavior is determined by a complex interaction of forces from multiple levels. There are a number of ways that youth development staff could promote (especially through healthy lifestyles initiatives) positive family interactions, emphasizing emotional and instrumental social support, for healthy eating. Below we list specific suggestions, arranged by SEM levels applicable to 4-H programs:

- Many youth organizations and clubs engage families. Club meetings and events that focus on healthy lifestyles could target specific nutrition behaviors through skill building sessions (e.g. creating snacks, planning meals, cooking, etc) and include components on how families support each other in these behaviors (individual/family/club levels);

- Older youth could be trained to lead/deliver these focused discussions, model healthy eating behaviors, and provide social support to their fellow club members (individual/family/club levels);

- Club meetings could include interactive discussion sessions on how families can provide emotional, coping, and instrumental support to one another (family/club levels);

- Clubs could initiate family oriented challenges so that families who change or increase healthy eating (and social support) receive special recognition or awards (family/club levels);

- Youth development organizations could partner with local extension community development agents and agricultural agents to link families to local healthy food sources and incorporate farm to table programs into club food services as a model to educate families on local farm to table programs (family/community levels);

- Summer programs and camps could more actively include/engage family members through a range of activities. For example, at the most basic level camps could communicate with parents (via newsletters, e-mails, parent materials that come home with each camper, etc) regarding healthy behaviors learned during camp and how to support the specific behaviors at home. At a more intensive level youth organizations and clubs could host family camp days or family camp weekends. Additionally, alumni camps targeting parents who were members of the club and their children can be an 
avenue to reach more families with healthy lifestyle messages (family/club/community levels);

- Ample opportunities exist through partnering with schools including health education classes, family nights, health fairs, and school-wide or district-wide healthy eating challenges (school/community levels).

The present study findings must be interpreted with caution for several reasons.

- First, the small sample size could account for the non-significant posttest change scores for Emotional Social Support for FV, Instrumental Social Support for FV and Instrumental Social Support for LFD.

- Second, the intervention dosage was once per week for five weeks. Perhaps meeting more than once per week and/or having a longer intervention could have lead to significant differences in other types of social support for the intervention group.

- Third, the intervention intended to change multiple behaviors (i.e., fruit/vegetable intake, low-fat dairy intake, physical activity) and researchers involved in large scale efficacy trials suggest long duration and great involvement is needed to change multiple behaviors (Edmundson, et al., 1996).

The intervention may have been more effective by focusing on only one behavior. This recommendation has also been noted by researchers involved in large-scale trials (Edmundson, et al., 1996).

Because little is known about emotional and instrumental social support for nutrition behaviors among African-American adolescents, these findings warrant further investigation. Although this was a pilot study, the significant effects observed are encouraging and suggests that familybased interventions with African-American families are both, feasible and are potentially effective avenues for promoting healthy eating. Future research should examine the effects of family-based nutrition promoting interventions focused on increasing social support for healthy nutrition behaviors with larger samples of African-American families and longer intervention durations. In addition, similar programs should be targeted to other ethnic/racial minority groups and mixed ethnic/race (several population groups together) groups and evaluated.

\section{References}

Appel, L.J., Moore, T.J., Obarzanek, E., Vollmer, W.M., Svetkey, L.P., Sacks, F.M., et al., (1997). A clinical trial of the effects of dietary patterns on blood pressure. New England Journal of Medicine, 336(16):1117-1124.

Bandura, A. (1986). Social Foundations of Thought and Action. Englewood Cliffs, NJ: Prentice Hall.

Baranowski, T., \& Nader, P.R. (1985). Family health behavior. In: Turk, D.C., Kerns, R.D. (Eds.) Health, IIlness, and Families: A Life-Span Perspective. New York: Wiley.

Barrera, M., \& Ainlay, S.L. (1983). The structure of social support: A conceptual and empirical analysis. Journal of Community Psychology, 11:133-143. 
Barrera, M., Sandler, I.N., \& Ramsay, T.B. (1981).Preliminary development of a scale of social support: Studies on college students. American Journal of Community Psychology, 9:435-447.

Brady, L.M., Lindquist, C.H., Herd, S.L., \& Goran, M.I. (2000). Comparison of children's dietary intake patterns with US dietary guidelines. British Journal of Nutrition. 84:361-367.

Carratero, O.A., \& Oparil, S. (2000). Essential hypertension. Part I: Definition and etiology. Circulation, 101(3):329-335.

Center for Nutrition Policy and Promotion. (2001). Report Card on the Diet Quality of Children Ages 2 to 9. U.S. Department of Agriculture. Available at: http://www.usda.gov/cnpp/Insights/Insight25.pdf.

Crockett, S.J., Mullis, R., Perry, C.L., \& Luepker, R.V. (1989). Parent education in youth-directed nutrition interventions. Preventive Medicine, 18(4):475-491.

Edmundson, E., Parcel, G.S., Feldman, H.A., Elder, J., Perry, C.L., Johnson, C.C., et al., (1996). The effects of the Child and Adolescent Trial for Cardiovascular Health upon psychosocial determinants of diet and physical activity behavior. Preventive Medicine, 25:442-454.

Food Surveys Research Group. (1999). Pyramid Servings Data: Results from USDA's 1994-96 Continuing Survey of Food Intakes by Individuals. U. S. Department of Agriculture. Available at: http://www.barc.usda.gov/bhnrc/foodsurvey/pdf/3yr py.pdf.

Fuller, K.E. (2003). Health disparities: Reframing the problem. Medical Science Monitor. 9(3):SR9-15.

Gillum, R.F. (1991). Cardiovascular disease in the United States: An epidemiologic overview. In E. Saunders (Ed.), Cardiovascular Diseases in Blacks. Philadelphia, PA: F. A. Davis Company.

Grunbaum, J., Kann, L., Kinchen, S.A., Williams, B., Ross, J.G., Lowry, R., \& Kolbe, L. (2002). Youth risk behavior surveillance -- United States 2001. MMWR Surveillance Summaries, 51(4):162.

Hanson, C.L., DeGuire, M.J., Schinkel, A.M., \& Kolterman, O.G. (1995). Empirical validation for a family-centered model of care. Diabetes Care, 18(10):1347-1355.

Kumanyika, S., \& Odoms, A. (2001). Nutrition. In S.E. Taylor (Ed.), Health Issues In the Black Community (Second ed.). San Francisco: Jossey-Bass Publishers.

McLeroy, K.R., Bibeau D., Steckler, A., \& Glanz, K. (1988). An ecological perspective on health promotion programs. Health Education Quarterly, 15(4):351-77.

Miller, G.D., Jarvis, J.K., \& McBean, L.D. (2001). The importance of meeting calcium needs with foods. Journal of the American College of Nutrition, 20(2):168S-185S.

Nader, P.R., Baranowski, J., Vanderpool, N.A., Dunn, K., Dworkin, R., \& Ray, L. (1983). The family health project: Cardiovascular risk reduction education for children and parents. Journal of Developmental Behavioral Pediatrics, 4:3-10. 
Nader, P.R., Sellers, D.E., Johnson, C.C., Perry, C.L., Stone, E.J., Cook, K.C., et al., (1996). The effect of adult participation in a school-based family intervention to improve children's diet and physical activity: The Child and Adolescent Trial for Cardiovascular Health. Preventive Medicine, 25:455-464.

Neumark-Sztainer, D., Story, M., Dixon, L.B., Resnick, M.D., \& Blum, R.W. (1997). Correlates of inadequate consumption of dairy products among adolescents. Journal of Nutrition Education and Behavior, 29:12-20.

Perry, C.L., Luepker, R.V., Murray, D.M., Kurth, C., Mullis, R., Crockett, S., \& Jacobs, D.R. (1988). Parent involvement with children's health promotion: The Minnesota Home Team. American Journal of Public Health, 78(9):1156-1160.

Roberts, M.C., \& Wallander, J.L. (1992). Family issues in pediatric psychology: An overview. In: Roberts, M.C., Wallander, J.L. (Eds.). Family Issues in Pediatric Psychology. Hillsdale, NJ: Lawrence Erlbaum Associates, Inc.

Sacks, F.M., Appel, L.J., Moore, T.J., Obarzanek, E., Vollmer, W.M., Svetkey, L.P., et al. (1999). A dietary approach to prevent hypertension: A review of the Dietary Approaches to Stop Hypertension (DASH) Study. Clinical Cardiology, 22(7suppl): III: 6-10.

Sacks, F.M., Svetkey, L.P., Vollmer, W.M., Appel, L.J., Bray, G.A., Harsha, D., et al. (2001). Effects on blood pressure of reduced dietary sodium and the Dietary Approaches to Stop Hypertension (DASH) diet. New England Journal of Medicine, 344(1):3-10.

Sallis, J.F., Grossman, R.M., Pinski, R.B., Patterson, T.L., \& Nader, P.R. (1987). The development of scales to measure social support for diet and exercise behaviors. Preventive Medicine, 16:825-836.

Sallis, J.F., \& Nader, P.R. (1988). Family determinants of health behaviors. In: Gochman, D.S., (Ed.). Health Behavior: Emerging Research Perspectives. New York: Plenum Press.

Standing Committee on the Scientific Evaluation of Dietary Reference Intakes, Food and Nutrition Board, \& Institute of Medicine. (1999). Dietary reference intakes for calcium, phosphorus, magnesium, vitamin D, and fluoride. Washington, DC: National Academy Press.

Stokols, D. (1996). Translating social ecological theory into guidelines for community health promotion. American Journal of Health Promotion, 10(4):282-98.

Svetkey, L.P., Simons-Morton, D.G., Vollmer, W.M., Appel, L.J., Conlin, P.R., Ryan, D.H., et al., (1999). Effects of dietary patterns on blood pressure: Subgroup analysis of the Dietary Approaches to Stop Hypertension (DASH) randomized clinical trial. Archives of Internal Medicine, 159(3):285-293.

U.S. Department of Health and Human Services. (December 1983). Health, United States, 1983 and Prevention Profile (PHS 84-1232).

Wadden, T.A., Stunkard, A.J., Rich, L., Rubin, C., Sweidel, G., \& McKinney, S. (1990). Obesity in Black adolescent girls: A controlled clinical trial of treatment by diet, behavior modification, and parental support. Pediatrics, 85(3):345-352. 
Wilson, D.K., \& Ampey-Thornhill, G. (2001). The role of gender and family support on dietary compliance in an African-American adolescent hypertension prevention study. Annals of Behavioral Medicine, 23:59-67.

Wilson, D.K., Evans, A.E., Williams, J.E., Praphul, J., Buck, J., \& Ehlers, M. (2004). Effects of a family-based intervention on diet and physical activity in African-American children.

International Society of Behavioral Nutrition and Physical Activity Conference, Washington, DC.

Wilson, D.K., Friend, R., Teasley, N., Green, S., Reaves, I.L., \& Sica, D.A. (2002). Motivational versus social cognitive interventions for promoting fruit and vegetable intake and physical activity in African-American adolescents. Annals of Behavioral Medicine, 24(4):310-319.

Wilson, D.K., Sica, D.A., \& Miller, S.B. (1999). Effects of potassium on blood pressure in saltsensitive and salt-resistant adolescents. Hypertension, 34:181-186.

(c) Copyright of Journal of Youth Development $\sim$ Bridging Research and Practice. Content may not be copied or emailed to multiple sites or posted to a listserv without copyright holder's express written permission. However, users may print, download or email articles for individual use. 